Regular Article

ISSN 1226-8267

Journal of Forest Science

Vol. 28, No. 3, pp. 158-169, August, 2012

http://dx.doi.org/10.7747/JFS.2012.28.3.158

\title{
Using High Resolution Ecological Niche Models to Assess the Conservation Status of Dipterocarpus lamellatus and Dipterocarpus ochraceus in Sabah, Malaysia
}

\author{
Colin R. Maycock ${ }^{1,2,}$, Eyen Khoo ${ }^{1}$, Chris J. Kettle ${ }^{3}$, Joan T. Pereira', John B. Sugau', Reuben Nilus ${ }^{1}$, \\ Jeisin Jumian ${ }^{1}$ and David F. R. P. Burslem ${ }^{2}$ \\ ${ }^{1}$ Forest Research Centre, Sabah Forest Department, Sanadkan, 90714, Malaysia \\ ${ }^{2}$ Institute of Biological and Environmental Sciences, University of Aberdeen, Cruickshank Building, St Machar Drive, Aberdeen, AB24 3UU, UK \\ ${ }^{3}$ Institute of Terrestrial Ecosystems, ETH Zïrich, CHN G 73.1, Universitätstrasse 16, Ziurich, 8092, Swoitzerland
}

\begin{abstract}
Sabah has experienced a rapid decline in the extent of forest cover. The precise impact of habitat loss on the conservation status of the plants of Sabah is uncertain. In this study we use the niche modelling algorithm MAXENT to construct preliminary, revised and final ecological niche models for Dipterocarpus lamellatus and Dipterocarpus ochraceus and combined these models with data on current land-use to derive conservation assessments for each species. Preliminary models were based on herbarium data alone. Ground surveys were conducted to evaluate the performance of these preliminary models, and a revised niche model was generated from the combined herbarium and ground survey data. The final model was obtained by constraining the predictions of the revised models by filters. The range overlap between the preliminary and revised models was 0.47 for D. lamellatus and 0.39 for $D$. ochraceus, suggesting poor agreement between them. There was substantial variation in estimates of habitat loss for $D$. ochraceus, among the preliminary, revised and constrained models, and this has the potential to lead to incorrect threat assessments. From these estimates of habitat loss, the historic distribution and estimates of population size we determine that both species should be classified as Critically Endangered under IUCN Red List guidelines. Our results suggest that ground-truthing of ecological niche models is essential, especially if the models are being used for conservation decision making.
\end{abstract}

Key Words: conservation status, dipterocarpaceae, ecological niche modeling, IUCN Red List, MAXENT

\section{Introduction}

Habitat loss is seen as one of the greatest threats to biodiversity in Borneo, because the annual rate of deforestation in Borneo is amongst the highest in the tropics (Sodhi et al. 2010). In Sabah, there has rapid decline in the extent of the natural forests, from about 86 percent in 1953 to less than
50 percent currently (McMorrow and Talip 2001; Reynolds et al. 2011). This decline is disproportionately high in the lowland coastal forests in the west and north of the state (Maycock et al. 2012). However, while the decline in forest cover is well documented, the overall impact of this forest loss on the conservation status of the plants of Sabah is largely unknown.

Received: June 12, 2012. Accepted: July 24, 2012.

Corresponding author: Colin R. Maycock

Forest Research Centre, Sabah Forest Department, Sandakan, 90714, Malaysia

Tel: 6089538202, Fax: 6089531068,E-mail: sepilokdata@gmail.com 
Target 12 of the Aichi Biodiversity Targets, set as part of the Strategic Plan for Biodiversity 2011-2020, calls for the prevention of the extinction of known threatened species, and an improvement of the conservation status of the most endangered species by the Year 2020 (Secretariat of the Convention on Biological Diversity 2010). The change in the IUCN Red List status is the accepted baseline to measure progress towards meeting this Target. The IUCN Red List of Threatened Species is designed to catalogue and highlight those plants and animals species that are at a high risk of global extinction (IUCN 2012). The Red List system classifies a species into one of nine categories: Not Evaluated (NE), Data Deficient (DD), Least Concern (LC), Near Threatened (NT), Vulnerable (VU), Endangered (EN), Critically Endangered (CR), Extinct in the Wild (EW) or Extinct (EX). Species that have adequate data and have been evaluated are classified into one of seven threat categories (LC, NT, VU, EN, CR, EW or $\mathrm{EX})$, based on at least one of the five assessment criteria. Further details on these criteria and the threshold values can be found in the Guidelines for Using the IUCN Red List Categories and Criteria (IUCN Standards and Petitions Subcommittee 2011).

One of the suggested milestones towards meeting Target 12 is a national assessment of the conservation status of all endangered species by the year 2014. Currently less than $5 \%$ of the plant species endemic to Sabah have been evaluated for the IUCN Red Lists (IUCN 2012; Maycock unpublished data). Ninety two percent of the assessments that have been conducted are listed as requiring updating and few of them provide any quantitative data to support the IUCN listing (IUCN 2012). This lack of quantitative data leads to uncertainty over the accuracy of the existing assessments (Chen 2004), and is a contributing factor to the lack of emphasis on the conservation of individual plant species in Malaysia (Ministry of Science, Technology and the Environment 1998; Chen 2004).

Sabah faces three distinct challenges in trying to provide quantitative assessment to serve as a baseline to assess progress towards meeting Target 12 . First, many plant species have a high degree of habitat specialisation (Ashton 2004) and as a consequence show disjunct distributions. The standard IUCN assessment tools based on estimating range from the extent of occurrence cannot accommodate disjunct distributions (Solano and Feria 2007; Maycock et al. 2012). Secondly, many of the plant species of highest conservation concern are often known from a single or a small number of collections, many of which were collected prior to the bulk of the forest loss in the State. This low sampling intensity leads to biased estimates of range size and potential habitat loss and can lead to inappropriate categorisation (Golding 2004). Finally, the high count of species in Sabah (6,000 to 8,000 plant species, including more than 800 species that are endemic), it would be impractical to conduct detailed assessments of all species by the 2014 deadline. Therefore alternative assessment strategies that are cost effective and feasible are needed to inform conservation decision making.

Ecological niche modelling has gained prominence as one possible alternative technique (Solano and Feria 2007; Feeley and Silman 2011a). This approach generates maps of a species' potential distribution on the basis of a mathematical representation of its distribution in environmental space (Phillips et al. 2006), and allows for the reconstruction of a species' historic distribution (Maycock et al. 2012). This species distribution model, coupled with current land-use maps, allows for the rapid assessment of the conservation status of tropical plants. Ecological niche models predict the fundamental niche of a species, which may differ from the realised niche and lead to an over-prediction of a species' distribution (Phillips et al. 2006). This over-prediction is usually removed from the final model by the development of suitable filters to constrain the prediction (Martínez-Meyer et al. 2006; Solano and Feria 2007; Lopez-Toledo et al. 2011). A further problem is that for many plant species, the ecological niche models are derived solely from herbarium collection data (e.g. Raes et al. 2009), and these collections may not represent the whole habitat range of a species. Many of these herbarium collections were made prior to the advent of GPS technology and need to be georeferenced post-collection (Beaman and Conn 2003), and this has the potential to add locational errors into the ecological niche models (Feeley and Silman 2010). Hence, the field validation of an ecological niche model should be an important step in the model development, particularly if the models are being used for conservation decision making. However, few studies undertake such surveys (Cayuela et al. 2009). 


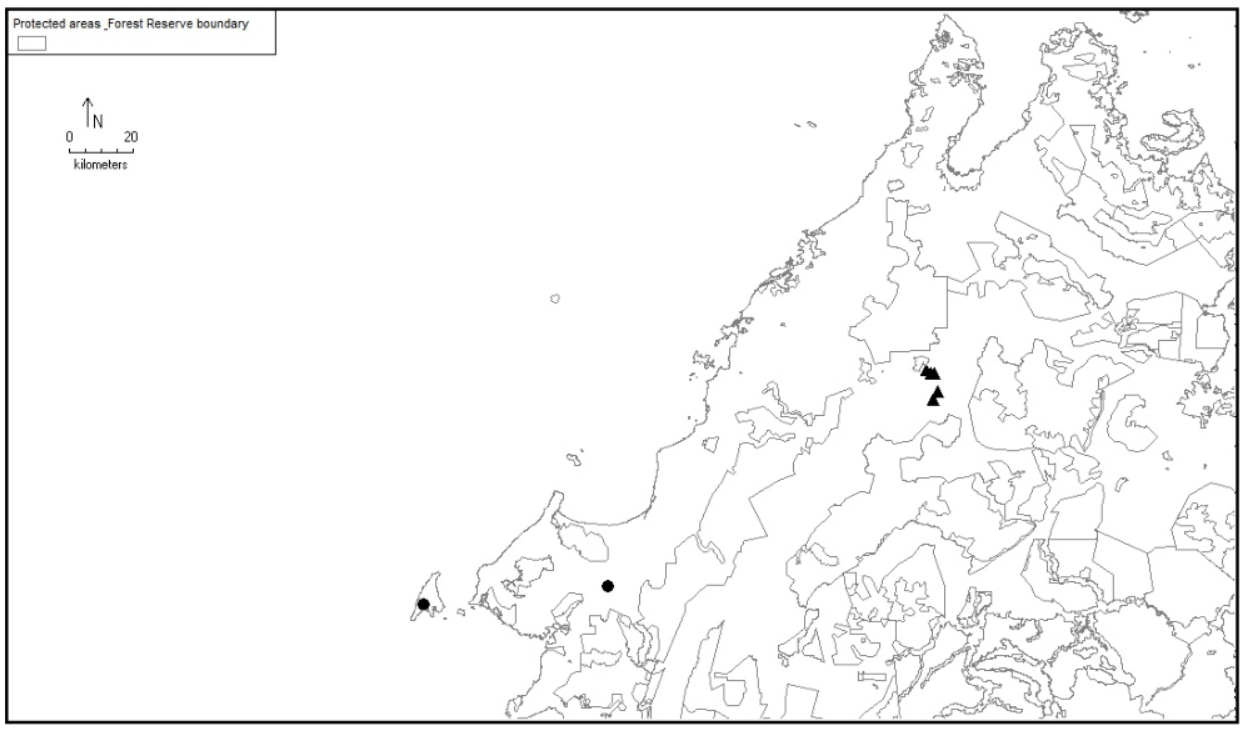

Fig. 1. Past collection localities of Dipterocarpus lamellatus (O) and Dipterocarpus ochraceus $(\boldsymbol{\Delta})$ in Sabah, Malaysia. The grey lines indicate the boundary of the production forests and protected areas in Sabah.
In this study we used herbarium data to develop preliminary ecological niche models for the Bornean endemic dipterocarps Dipterocarpus lamellatus and Dipterocarpus ochraceus. These models were used to select sites for prospective sampling and ground-truthing of the models. The field survey data were then used to develop second generation ecological niche models and devise filters to constrain the model predictions for each species. We estimated the population size and recruitment success following a major masting event for these two species, and derived conservation assessments based on the estimates of habitat loss, geographic range and the size of the remaining populations.

\section{Materials and Methods}

\section{Study species}

The two study species selected are of high conservation concern. Dipterocarpus lamellatus is one of the rarest and most endangered of all dipterocarps (Ashton 2004). It was known from only three confirmed collecting localities, Ladan Hills in Brunei Darussalam, Labuan Island, Malaysia and Beaufort Hills in Sabah, Malaysia (Fig. 1), with two unconfirmed, and highly unlikely, records from central Kalimantan (P.S. Ashton pers. comm.). The most recent collection of this species in Sabah was from the Beaufort Hills in 1955 and it was considered to be locally extinct in Sabah (Ashton 2004). The species is currently classified as critically endangered A1cd $+2 c d, B 1+2 c, C 1$, D on the IUCN Red List (Ashton 1998), although no quantitative data were provided to support the assessment and the assessment is listed as needing upgrading (IUCN 2012).

Dipterocarps ochraceus is known from four collection localities in Sabah (Fig. 1), and from these collections it appears that $D$. ochraceus is an extremely narrow range endemic restricted to a narrow altitudinal band between 600 and $700 \mathrm{~m}$ above sea level (asl) on the ultrabasic and basic volcanic soils of the flanks of Mt Kinabalu (Ashton 2004). While it has not been assessed for the IUCN Red List, most of the previous collections of $D$. ochraceus were outside the National Park and most of this habitat has been converted to alternative land-uses.

\section{Development of ecological niche models}

Preliminary ecological niche models were generated using MAXENT v. 3.3.1 (www.cs.princeton.edu/-schapire/maxent/, Phillips et al. 2006) based on locality data obtained from herbarium specimens. As all of the herbarium specimens were collected in the 1960s, or earlier, and were without geographical coordinates, we assigned coordinates to these collection using the information contained on the specimen label in consultation with 1:250,000 soil maps and 1:50,000 forest stratum maps. Where multiple specimens had been collected from the same soil type in one lo- 
cality (corresponding to a $2 \times 2 \mathrm{~km}$ grid cell on a map of Sabah), only one sample was included in the analysis to reduce sampling bias (Hijmans et al. 2000). Conversely, collections from more than one soil type within a $2 \times 2 \mathrm{~km}$ grid cell were included as independent items of data for constructing species distributions.

The ecological niche models were developed using bioclimatic, altitudinal and edaphic variables as outlined in Maycock et al. (2012). Bioclimatic data for Sabah at $30 \mathrm{arc}$ seconds $\left(-1 \mathrm{~km}^{2}\right)$ resolution were obtained from WorldClim (www.worldclim.org). Shuttle Mission Radio Telemetry altitudinal data at three arc-second resolution ( -90 by $90 \mathrm{~m}$ ) were obtained from the CGIAR-CSI GeoPortal (srtm.csi.cgiar.org). The slope of the terrain was calculated from the altitudinal data using ArcView 3.3. GIS shapefiles of soil association, landform, soil suitability and soil parent material digitised from the Soils of Sabah maps (Acres et al. 1975 ) were obtained from the Sabah Forestry Department. The shapefiles were converted to ESRI ASCII grid format using ArcView Spatial Analyst. All spatial data were on the WGS84 projection. As the edaphic variables are categorical and cannot be aggregated into larger mapping units, it was necessary to set the grid size to the smallest common size of 6 arc seconds $\left(-0.04 \mathrm{~km}^{2}\right)$.

We ran 100 replicated runs of MAXENT on the locality data with 10,000 background points randomly selected per run (Phillips et al. 2006). The average predicted distribution from 100 replicated runs of MAXENT was used as an estimate of the total historic distribution of each species.

\section{Field surveys}

We used the preliminary niche models and satellite images to develop a prospective sampling strategy for both species (Cayuela et al. 2009). Sites where the target species was predicted to be either present or absent were selected, although the number of sites surveyed and selection of the sites was also constrained by the availability of natural forest. For $D$. Ochraceus, surveys were conducted at 17 sites covering four soil associations and between 430 and $1900 \mathrm{~m}$ asl (Appendix 1). For D. lamellatus, as there is little natural lowland forest remaining in the southwest of Sabah, we were restricted to five survey sites on three soil associations at altitudes between 10 and $350 \mathrm{~m}$ asl (Appendix 1). At these sites we walked transects of between 0.25 and $4.5 \mathrm{~km}$ length and approximately $50 \mathrm{~m}$ wide, and conducted inventories of all dipterocarps species. The sites were then classified into false and true positives and negatives depending on whether we encountered the target species or not. At sites where we encountered the target species, detailed surveys were conducted to obtain an estimate of the size of the population, and the position of all trees greater than $40 \mathrm{~cm}$ dbh were GPSed.

\section{Seedling recruitment during a general flowering event}

During the general flowering event in 2010 we resurveyed all adult trees of Dipterocarpus ochraceus for signs of flowering. The flowering trees were revisited at the end of the seedfall (October 2010) and four $4 \mathrm{~m}^{2}$ seedling plots established under each tree that had flowered following the procedure outlined in Maycock et al. (2005). For Dipterocarpus lamellatus, we surveyed an area of approximately 0.78 ha around each tree for signs of recruitment approximately five months after the completion of seedfall (February 2011).

\section{Conservation assessments}

The new collection localities were combined with the herbarium data to develop a second generation niche model following the procedure outlined above. We then estimated the species geographic range based on the preliminary and revised models and compared the range-overlap using ENMTools 1.3 (Warren et al. 2008; 2010). Estimates of range overlap range from 0 to 1 , with 1 representing perfectly overlapping models (Warren et al. 2010).

The false positive data obtained during the field surveys were used to generate filters to remove the over-predictions by the model (Solano and Feria 2007), and a constrained prediction of the distribution of $D$. ochraceus was generated. The filters excluded all areas higher than $950 \mathrm{~m}$ asl and areas on the western and northern parts of the Kinabalu Park. A current land use map was overlaid on the preliminary, revised and constrained predicted distributions and an estimated percentage habitat loss determined as outlined in Maycock et al. (2012). Due to the localised predicted distribution and the lack of sites still retaining forest, we could not develop filters for $D$. lamellatus, so our comparison was 
Table 1. Performance of the preliminary ecological niche models at predicting the occurrence of Dipterocarpus lamellatus and Dipterocarpus ochraceus. Positive refers to sites where the species is predicted to be present and negative where the niche model predicts the species should be absent

\begin{tabular}{lcccccc}
\hline \multirow{2}{*}{ Species } & \multicolumn{4}{c}{$\begin{array}{c}\text { Preliminary ecological niche model } \\
\text { prediction }\end{array}$} \\
\cline { 2 - 3 } \cline { 5 - 6 } & \multicolumn{2}{c}{ Positive } & & \multicolumn{2}{c}{ Negative } \\
\cline { 2 - 3 } \cline { 5 - 6 } & True & False & & True & False \\
\hline Dipterocarpus lamellatus & 1 & 1 & & 2 & 1 \\
Dipterocarpus ochraceus & 1 & 5 & & 8 & 3 \\
\hline
\end{tabular}

restricted to the preliminary and revised models.

We classified both species into IUCN threat categories based on estimated area of habitat loss, size of geographic range and estimates of population size (IUCN Standards and Petitions Subcommittee 2011). The distributions used to infer habitat loss and range size were derived from the revised model for $D$. lamellatus and the constrained model for D. ochraceus.

\section{Results}

\section{Ground-truthing and comparison of models}

The preliminary ecological niche model for $D$. lamellatus predicted only three of the five sampling areas successfully, with one false positive and one false negative (Table 1). The range comparison between the preliminary and revised model was 0.47 . However, the limited overlap between the models did not lead to a large difference in the estimates of habitat loss, which were 99.6 and $98.0 \%$, respectively for the preliminary and revised ecological niche models (Fig. 2).

In contrast, there were large differences in the estimates of habitat loss between the preliminary $(27.1 \%)$, revised $(45.1 \%)$ and constrained (68.9\%) ecological niche models for $D$. ochraceus. The estimates of area occupied by $D$. ochraceus varied from $78 \mathrm{~km}^{2}$ for the constrained model to $488 \mathrm{~km}^{2}$ for the revised model (Fig. 3). The preliminary ecological niche model for $D$. ochraceus predicted nine of the 17 sampling areas successfully, with five false positive and three false negatives (Table 1). The range comparison between the preliminary and revised model was 0.39 .

\section{Conservation assessments}

Approximately $98 \%$ of the area that Dipterocarpus lamellatus was predicted to have previously occupied in Sabah $\left(350 \mathrm{~km}^{2}\right.$ ) has been converted to alternative land uses (Fig. $2 B$ ). Ground surveys have located only three mature individuals within the Sianggau Forest Reserve, with no signs of seedling recruitment (Table 2). Based on the small number of individuals and the amount of habitat loss we classify this species as Critically Endangered A2c, C1ai+aii, D1.

Dipterocarpus ochraceus was predicted to have previously occupied an area of $78 \mathrm{~km}^{2}$ in Sabah (Fig. 3C), but approximately $68 \%$ of this area has been lost. Ground surveys have located three populations of Dipterocarpus ochraceus. Two of these populations occur within the Kinabalu Park and consist of 41 and 8 individuals, respectively (Table 2). Both populations have signs of recent recruitment with an average seedling density of 0.11 and 0.26 seedlings $\mathrm{m}^{-2}$, respectively. The third population is a small remnant stand of three individuals outside the Hampuan Forest Reserve, with no signs of recruitment. Based on the small area of remaining habitat within the predicted historic distribution we classify this species as Critically Endangered B2.

\section{Discussion}

\section{Ground truthing niche models}

The low range overlap between the preliminary and the revised models suggests that there were substantial differences in the predicted distribution generated from the two different datasets for both species. These differences may have arisen because the collections represented by the herbarium specimens do not sample the full range of habitats occupied by these species, and/or because the low number of samples was insufficient to generate accurate models. Collection localities for herbarium specimens tend to be clumped around more accessible areas close to towns (Tobler et al. 2007). For example, in Sabah over 16\% of all the dipterocarp specimens in the Sandakan herbarium are from the Sandakan district, which occupies only about 3\% of the state.

The accuracy of the predictions from ecological niche models increases with increasing sample size (Feeley and Silman 2011a), and this may also contribute to the discrep- 


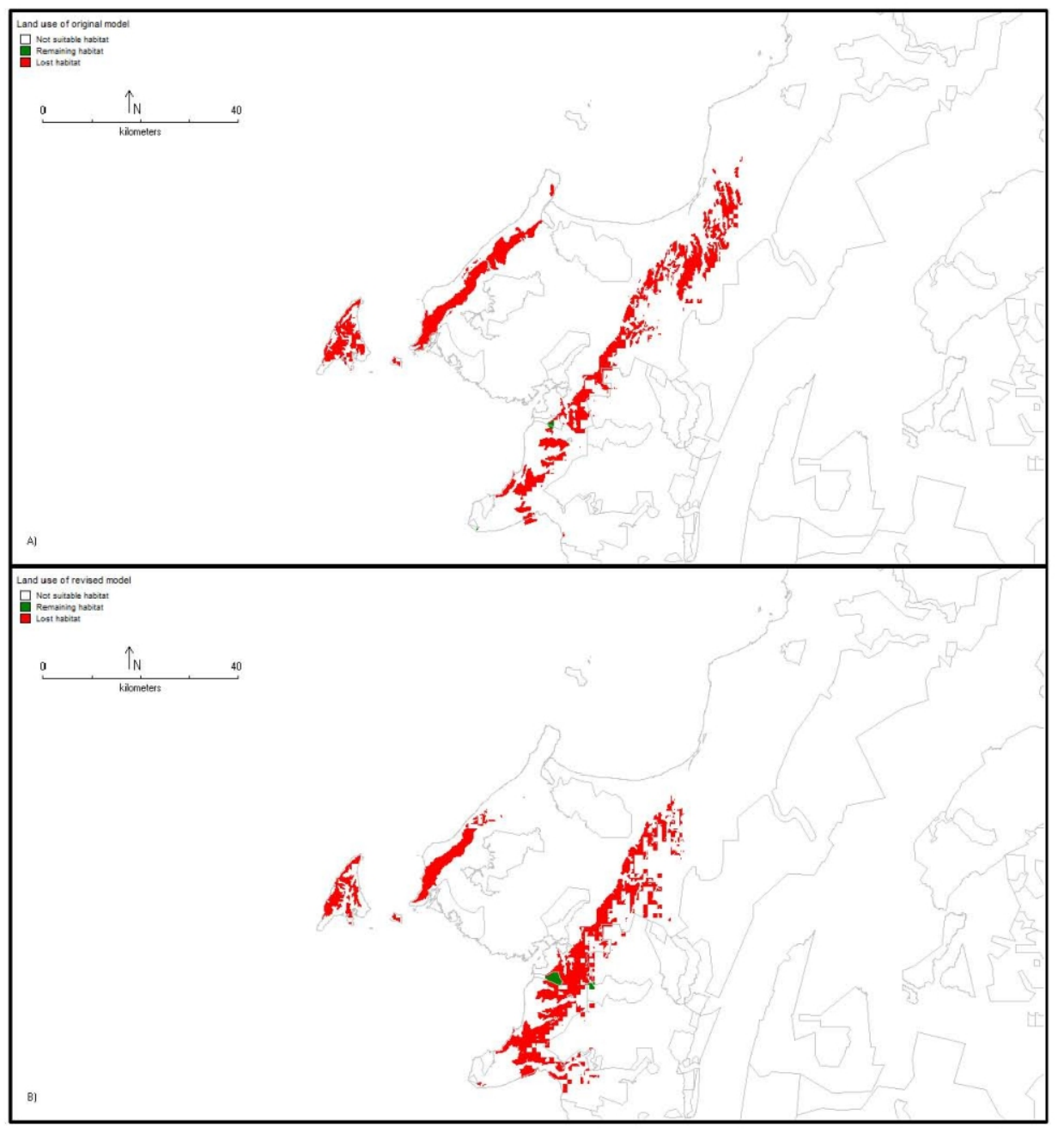

Fig. 2. The predicted distribution of Dipterocarpus lamellatus in Sabah for (A) the preliminary model based on the herbarium records only and (B) revised model based on the herbarium records and new collections. The coloured areas represent the historic distribution of the species, with red indicating areas that have been converted to alternative land use and green indicating areas within protected areas. The grey lines indicate the boundary of the production forests and protected areas in Sabah. ancy between the preliminary and revised niche models in our study. Our preliminary ecological niche models for $D$. lamellatus and $D$. ochraceus were generated using two and four collection localities, respectively. These numbers are well below the minimum sample size of 20 collection localities suggested by Feeley and Silman (2011b), they represent all the known collections for these species at that time. This paucity of data is a problem faced by most tropical countries, as over $90 \%$ of tropical plant species are represented by less than 20 collection localities (Feeley and Silman 2011b). To generate the datasets require to accurately map a species' range requires larger samples sizes and better distributed collecting effort (Feeley and Silman 2011a).

Both the preliminary and revised models for $D$. ochraceus include areas on the western side of the Kinabalu Park (Fig. $3 \mathrm{~A}, \mathrm{~B})$, where our surveys and extensive past surveys highlighted in Beaman et al. (2001) have failed to locate this species. While it is possible that the species does occur in this area, it is more likely that the niche model is over-predicting the distribution of $D$. ochraceus. This over-prediction leads to substantial differences in estimates of habitat loss and could result in an incorrect threat assessment. Broad scale over-prediction by ecological niche models is a well-recognised problem that is often relatively easy to solve (Solano and Feria 2007), but finer scale over-predictions present a more difficult problem that can only be addressed by ground-truthing of the model (Cayuela et al. 2009).

The ground-truthing of the preliminary models showed that they failed to predict the occurrence of $D$. lamellatus 


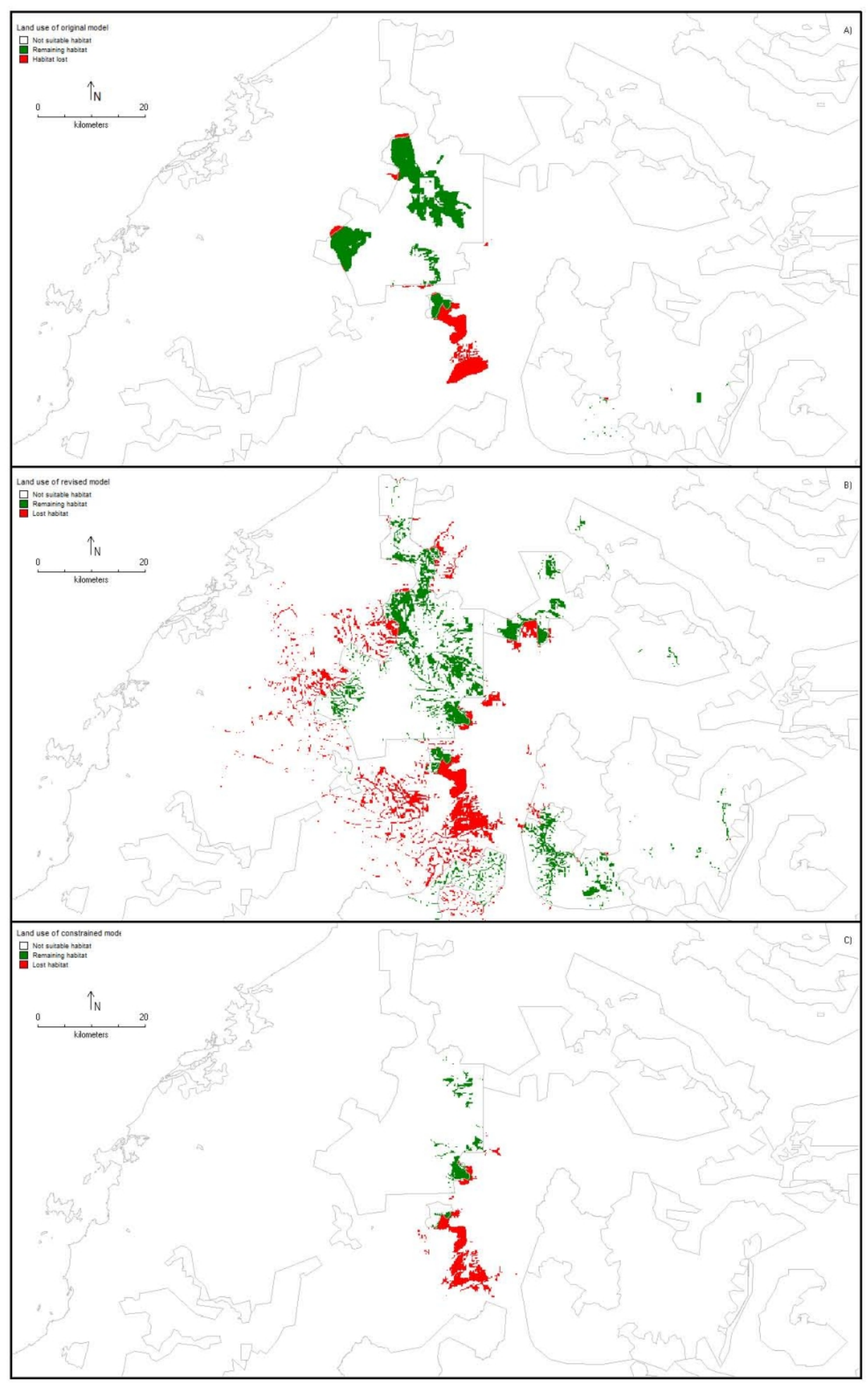

Fig. 3. The predicted distribution of Dipterocarpus ochraceus in Sabah for (A) the preliminary model based on the herbarium records only, (B) revised model based on the herbarium records and new collections and (C) the constrained model based on the combined datasets and ground truthing. The coloured areas represent the historic distribution of the species, with red indicating areas that have been converted to alternative land use and green indicating areas within protected areas. The grey lines indicate the boundary of the production forests and protected areas in Sabah. 
Table 2. Predicted area of the historic distribution, estimates of habitat loss and population size of Dipterocarpus lamellatus and Dipterocarpus ochraceus in Sabah

\begin{tabular}{lcccccc}
\hline Species & $\begin{array}{c}\text { Predicted area of } \\
\text { the historic } \\
\text { distribution } \\
\left(\mathrm{km}^{2}\right)\end{array}$ & $\begin{array}{c}\text { Estimated } \\
\text { habitat loss } \\
(\%)\end{array}$ & $\begin{array}{c}\text { Number of } \\
\text { populations }\end{array}$ & $\begin{array}{c}\text { Number of } \\
\text { mature } \\
\text { individuals in } \\
\text { each population }\end{array}$ & $\begin{array}{c}\text { Number of the } \\
\text { trees that fruited }\end{array}$ & $\begin{array}{c}\text { Number of new } \\
\text { recruits per } \mathrm{m}^{2}\end{array}$ \\
\hline Dipterocarpus lamellatus & 350 & 98 & 2 & 1 & 1 & 0 \\
Dipterocarpus ochraceus & 78 & 62 & 3 & 3 & 0 & 0 \\
& & & & 41 & 0 & $0.11 \pm 0.1$ \\
\end{tabular}

and $D$. ochraceus at one and three sites, respectively (Table 1). These sites occurred on soil associations where the species had not previously been collected. This failure to predict the species occurrence on uncollected habitat is a consequence of the use of categorical edaphic variables during model construction (Maycock et al. 2012). While preliminary analysis shows that using lower resolution soil information, e.g. the Harmonised World Soil Data, (FAO/ IIASA/ISRIC/ISSCAS/JRC, 2012) reduces the frequency of false negatives, it also leads to a marked increase in the number of false positives because many areas of habitat that is unsuitable for dipterocarps (e.g. Mangroves) are included within the predicted distributions (Nazahatul Anis Amaludin, personal communication).

Ground-truthing of ecological niche models should be an integral step in niche model development and testing (Cayuela et al. 2009). However, ground-truthing is time consuming and costly: the field testing of the preliminary niche models developed in this study took 28 field days and cost - USD 4,030 in field allowances and consumables. The estimated number of plant species occurring in Sabah is between 6,000 and 8,000 species, of which at least 800 are endemic to the Sabah (Maycock unpublished data). Therefore it is unlikely that detailed field testing will be possible for the majority of species without the collaboration of industrial partners and the general public. Amateur botanists are already an important source of information for charismatic plant groups e.g. Orchids, Hoya spp. Nepenthes spp., within the State, however, currently there are no State-wide mechanisms to record their observations or to involve them within these conservation programs.

To generate the datasets required to map a species' range accurately, develop quantitative conservation assessments and allow for niche model testing there needs to be an improvement in data access and sharing among different plant researchers within Sabah and Borneo. Currently, a duplicate of all plant collections made in Sabah must be deposited in at least one of the three herbaria in the state, but there is no such requirement to archive ecological plot data and other secondary sources of plant distributional data. One way to centralise these data would be to develop a regional network along the lines of VertNet (Constable et al. 2010). VertNet is a collaborative network of the vertebrate natural history collections, which collates global vertebrate biodiversity data and provides a publicly accessible database (Constable et al. 2010).

\section{Conservation status of Dipterocarpus lamellatus and Dipterocarpus ochraceus in Sabah}

Target 12 of the Aichi Biodiversity Targets calls for a halt in the decline in the conservation status of endangered species by the Year 2020 (Secretariat of the Convention on Biological Diversity 2010). Achieving this target will require quantitative assessments that allow for identification of those species most at risk and the areas that are important for their conservation. Without this information, these species and areas cannot be incorporated into the conservation decision making processes, and we risk losing many plant species from Sabah. Target 12 also calls for an improvement in the conservation status of those species most in decline by the 2020 deadline (Secretariat of the Convention on Biological Diversity 2010), which may prove more difficult to achieve for many plant species in Borneo. Dipterocarps, and many other plant families in Borneo, undergo a re- 
productive phenomenon known as general flowering (Ashton et al. 1988). This is a synchronised community-wide reproductive event that occurs at irregular intervals ( 2 to 7 year), and is often the only time these species recruit successfully (Curran and Leighton 2000). While there appears to be some association of general flowering with El Niño events, their incidence is largely unpredictable and this makes planning of conservation and restoration activities difficult (Kettle 2010). Furthermore, vegetative propagation of dipterocarps using cuttings derived from seedlings is possible, but the likelihood of success decreases with the age of the source material (Itoh et al. 2003 ). Hence it might be possible to propagate $D$. ochraceus from the new seedlings we observed, but the absence of $D$. lamellatus seedlings (Table 2) restricts the options for improving the status of this species and places a greater emphasis on the protection and augmentation of the remaining population.

The only remaining individuals of Dipterocarpus lamellatus in Sabah occur in the Sianggau Forest Reserve, which is a small reserve of approximately 840 ha. Areas of this reserve were burnt during the 1982/83, 1997/98 and $2010 \mathrm{El}$ Niño events, and fire remains a long-term threat to the survival of this species. To ensure persistence of this species, restoration of the Sianggau Forest Reserve must be given a high priority. Much of the Sianggau FR is currently dominated by pyrophytic species such as Acacia mangium, Dicranopteris spp. and Imperata cylindrica. Previous work has shown that the presence of these species increases the reoccurrence of fire (Cohen et al. 1995). A forest restoration strategy that leads to development of a multi-layered canopy would reduce the incidence of fire and lead to an improve likelihood of the survival of $D$. lamellatus. The small number and low density of $D$. lamellatus found within this reserve also raises some concerns about the long-term viability of the population in Sabah. Further surveys within the Sianggau reserve are required to locate any other individuals of $D$. lamellatus.

Species restricted to a single forest reserve are likely to be more vulnerable to extinction due to the consequences of small population size and stochastic factors (Purvis et al. 2000 ), and thus the establishment of additional populations in new sites is required. The ecological niche model suggests that suitable habitat is available in the low elevation portion of the Sipitang Forest Reserve (Fig. 2B). This area is currently under industrial tree plantation, but by working with Sabah Forest Industries Sdn Bhd (SFI), the concessionaire, it may be possible to conduct restoration plantings of this species. However, this will be dependent on the availability of suitable planting material as discussed above.

Apart from Sabah, Dipterocarpus lamellatus has been collected previously from Ladan Hills in Brunei Darussalam, although currently there is no information on whether this species still occurs in that area, or the size or viability of the population. If the species still occurs in Brunei Darussalam, there needs to be some consideration of managing these two populations as a metapopulation, including the exchange of genetic material among the two populations. While there are some cross-border conservation initiatives in Borneo e.g. Heart of Borneo (Sabah Forestry Department and WWF-Malaysia 2009), there are few examples of on-going cross-border plant species conservation programs and whether this is politically possible remains uncertain. Furthermore, while this may increase the effective breeding size of the population, there is a risk of introducing genotypes that are ill adapted for the local conditions.

While Dipterocarpus ochraceus has suffered a large reduction in its distribution, the two most important remaining population are in the Kinabalu Park, which is strictly protected. The management of the Kinabalu Park has generally been effective in protecting forest environments, although there are signs of fire damage along the eastern border of the Park (Phua et al. 2008). These fires were initiated by slash and burn agriculture in the areas bordering the Park (Phua et al. 2008). The long-term survival of $D$. ochraceus is dependent on reducing the fire risk around the Park, either though integrated fire management and/or by encouraging a switch to commercial tree crops in the areas adjacent to the Kinabalu Park. The availability of suitable habitat to establish other populations of $D$. ochraceus is fairly limited (Fig. 3C), as most of the area lost is privately owned land.

\section{Conclusions}

Conservation planning requires detailed information on which species are most endangered and where they occur. Currently most tropical plant species are essentially in- 
visible to modern conservation tools (Feeley and Silman $2011 \mathrm{~b}$ ). We require larger sample sizes and more widely distributed collecting effort to ensure more accurately mapped species ranges (Feeley and Silman 2011a). To achieve this we need closer collaboration and data sharing amongst tropical plant researchers and an expansion of collection effort.

The conservation of $D$. lamellatus and other critically endangered plant species in Sabah and Borneo requires the identification of those species most at risk and the ability to take advantage of general flowering events. Kettle et al. (2011) highlighted that opportunities for plant conservation in Borneo provided by the 2010 general flowering were missed because of a lack of resources, combined with a poor understanding of those plant species most at risk. Consequently, the opportunity to improve the conservation status of the many plant species in decline in Sabah and Borneo was also missed. Whether another general flowering will occur before the 2020 deadline is not known, but without the quantitative assessments showing which species are the most highly threatened, information on where these species occur and on-going monitoring programs in place we will lose the opportunities for scaling-up planting programs provided by future general flowering events.

\section{Acknowledgements}

We thank the numerous Forestry Research Centre staff who have contributed to the recent surveys. The project would not have been possible without the dedicated plant collecting efforts of the numerous past and present forest botanists, ecologists, foresters, tree climbers and research assistants of the Sabah Forestry Department. We thank the Director of Forestry Datuk Sam Mannan for support. This work was supported by the Sabah State Government by a grant award to EK under the $9^{\text {th }}$ and $10^{\text {th }}$ Malaysia Plans, a grant from the UK Natural Environment Research Council to DB.

\section{References}

Acres BD, Bower RP, Burrough PA, Folland CJ, Kalsi MS, Thomas P, Wright PS. 1975. The soils of Sabah. Volume 1. Classification and description (with an introduction to Volumes
1-5). Land Resource Study 20, Land Resources Division, Surrey, England.

Ashton PS, Givnish TJ, Appanah S. 1988. Staggered Flowering in the Dipterocarpaceae: New Insights into floral induction and the evolution of mast fruiting in the aseasonal tropics. American Naturalist 132: 44-66.

Ashton PS. 1998. Dipterocarpus lamellatus. In: IUCN 2011. IUCN Red List of Threatened Species. Version 2011.2. http://www. iucnredlist.org. Accessed 1 Mar 2012.

Ashton PS. 2004. Dipterocarpaceae. In: Tree flora of Sabah and Sarawak, Volume 5 (Soepadmo E, Saw LG, Chung RCK, eds). Forest Research Institute Malaysia, Kuala Lumpur, Sabah Forestry Department, Sandakan and Sarawak Forestry Department, Kuching, Malaysia, pp 63-388.

Beaman JH, Anderson C, Beaman RS 2001. The plants of Mount Kinabalu, 4. Dicotyledon families Acanthaceae to Lythraceae. Kota Kinabalu Natural History Publications (Borneo) in association with The Royal Botanic Gardens, Kew xiv, 570.

Beaman RS, Conn BJ. 2003. Automated geoparsing and georeferencing of Malesian collection locality data. Telopea 10: 43-52.

Cayuela L, Golicher DJ, Newton AC, Kolb M, de Alburquerque FS, Arets EJMM, Alkemade, JRM, Pérez AM. 2009. Species distribution modeling in the tropics: problems, potentialities, and the role of biological data for effective species conservation. Trop Conserv Sci 2: 319-352.

Chen HK. 2004. A Malaysian assessment of The World List of Threatened Trees. http://www.traffic.org/forestry-reports/traffic pub forestry1.pdf. Accessed 28 Nov 2010.

Cohen AL, Singhakumara BMP, Ashton PMS. 1995. Releasing rain forest succession: a case study in the. Dicranopteris linearis fernlands of Sri Lanka. Restor Ecol 3: 261-270.

Constable H, Guralnick R, Wieczorek J, Spencer C, Peterson AT; VertNet Steering Committee. 2010. VertNet: a new model for biodiversity data sharing. PLoS Biol 8: e1000309.

Curran LM, Leighton M. 2000. Vertebrate responses to spatiotemporal variation in seed production of mast-fruiting Dipterocarpaceae. Journal Ecological Monographs 70: 101-128.

FAO/IIASA/ISRIC/ISSCAS/JRC. 2012. Harmonized World Soil Database (version 1.2). FAO, Rome, Italy and IIASA, Laxenburg, Austria. http://www.iiasa.ac.at/Research/LUC/External-World-soil-database/HTML. Accessed 12 April 2012.

Feeley KJ, Silman MR. 2010. Modelling the responses of Andean and Amazonian plant species to climate change: the effects of georeferencing errors and the importance of data filtering. Journal of Biogeography 37: 733-740.

Feeley KJ, Silman MR. 2011a. Keep collecting: accurate species distribution modelling requires more collections than previously thought. Divers Distrib 17: 1132-1140.

Feeley KJ, Silman MR. 2011b. The data void in modeling current and future distributions of tropical species. Global Change Biology 17: 626-630.

Golding JS. 2004. The use of specimen information influences the 
outcomes of Red List assessments: the case of southern African plant specimens. Biodiversity \& Conservation 13: 773-780.

Hijmans RJ, Garrett KA, Huaman Z, Zhang DP, Schreuder M, Bonierbale M. 2000. Assessing the geographical representativeness of genebank collections: the Bolivian wild potatoes. Conserv Biol 14: 1755-1765.

Itoh A, Yamakura T, Tan S, Kendawang JJ, Lee HS. 2003. Effects of resource plant size on rooting of Dryobalanops lanceolata cuttings. J For Res 8: 117-121.

IUCN Standards and Petitions Subcommittee. 2011. Guidelines for using the IUCN Red List categories and criteria. Version 9.0. Prepared by the Standards and Petitions Subcommittee. http://www.iucnredlist.org/documents/RedListGuidelines.pdf. Accessed 23 Feb 2012.

IUCN. 2012. IUCN Red List of Threatened Species. Version 2012.3. http://www.iucnredlist.org. Accessed 23 Feb 2012.

Kettle CJ. 2010. Ecological considerations for using dipterocarps for restoration of lowland rainforest in Southeast Asia. Biodivers Conserv 19:1137-1151

Kettle CJ, Ghazoul J, Ashton P, Cannon CH, Chong L, Diway B, Faridah E, Harrison R, Hector A, Hollingsworth P, Koh LP, Khoo E, Kitayama K, Kartawinata K, Marshall AJ, Maycock C, Nanami S, Paoli G, Potts MD, Samsoedin I, Sheil D, Tan S, Tomoaki I, Webb C, Yamakura T, Burslem DFRP. 2011. Seeing the fruit for the trees in Borneo. Conservation Letters 4: 184-191.

Lopez-Toledo L, Gonzalez-Salazar C, Burslem DFRP, MartinezRamos M. 2011. Conservation assessment of Guaiacum sanctum and $G$. coulteri: historic distribution and future trends in Mexico. Biotropica 43: 246-255.

Martínez-Meyer E, Peterson AT, Jorge I. Servín JI, Kiff LF. 2006. Ecological niche modelling and prioritizing areas for species reintroductions. Oryx 40: 411-418.

Maycock CR, Kettle CJ, Khoo E, Pereira TJ, Sugau BJ, Nilus R, Ong RC, Amaludin NA, Newman MF, Burslem DFRP. 2012. A Revised Conservation Assessment of Dipterocarps in Sabah. Biotropica DOI: 10.1111/J.1744-7429.2011.00852.X

Maycock CR, Thewlis RN, Ghazoul J, Nilus R. Burslem DFRP. 2005. Determinants of recruitment success among 17 dipterocarp species during low intensity flowering events in Borneo. J Vegetation Sci 16: 635-646.

McMorrow J, Talip MA. 2001. Decline of forest area in Sabah, Malaysia: relationship to state policies, land code and land capability. Global Environmental Change 11: 217-230.

Ministry of Science, Technology and the Environment. 1998.
National Policy in Biological Diversity. http://www.arbec.com. my. Accessed 28 Nov 2010.

Phillips SJ, Anderson RP, Schapire RE. 2006. Maximum entropy modeling of species geographic distributions. Ecol Model 190: 231-259.

Phua MH, Tsuyuki S, Furuya N, Lee JS. 2008. Detecting deforestation with a spectral change detection approach using multitemporal Landsat data: a case study of Kinabalu Park, Sabah, Malaysia. J Environ Manage 88: 784-795.

Purvis A, Gittleman JL, Cowlishaw G, Mace GM. 2000. Predicting extinction risk in declining species. Proc Biol Sci 267: 1947-1952.

Raes N, Roos MC, Slik JWF, van Loon EE, ter Steege H. 2009. Botanical richness and endemicity patterns of Borneo derived from species distribution models. Ecography 32: 180-192.

Reynolds G, Payne J, Sinun W, Mosigil G, Walsh RP. 2011. Changes in forest land use and management in Sabah, Malaysian Borneo, 1990-2010, with a focus on the Danum Valley region. Philos Trans R Soc Lond B Biol Sci 366: 3168-3176.

Sabah Forestry Department, WWF-Malaysia. 2009. Strategic plan of action (Sabah) The Heart of Borneo Initiative. Sabah Forestry Department.

Secretariat of the Convention on Biological Diversity. 2010. Proposals for a consolidated update of the Global Strategy for Plant Conservation 2011-2020. Secretariat of the Convention on Biological Diversity.

Sodhi NS, Posa MRC, Lee TM, Bickford D, Koh LP, Brook BW. 2010. The state and conservation of Southeast Asian Biodiversity. Biodiversity Conserv 19: 317-328.

Solano E, Feria TP. 2007. Ecological niche modeling and geographic distribution of the genus Polianthes L. (Agavaceae) in Mexico: using niche modeling to improve assessments of risk status. Biodiversity Conserv 16: 1885-1900.

Tobler M, Honorio E, Janovec J, Reynel C. 2007. Implications of collection patterns of botanical specimens on their usefulness for conservation planning: an example of two neotropical plant families (Moraceae and Myristicaceae) in Peru. Biodiversity Conserv 16: 659-677.

Warren DL, Glor RE, Turelli M. 2008. Environmental niche equivalency versus conservatism: quantitative approaches to niche evolution. Evolution 62: 2868-2883.

Warren DL, Glor RE, Turelli M. 2010. ENMTools: a toolbox for comparative studies of environmental niche models. Ecography 33: 607-611. 
Appendix 1. List of sites surveyed

\begin{tabular}{|c|c|c|c|c|c|c|c|}
\hline & \multirow{3}{*}{$\begin{array}{l}\text { Length of } \\
\text { transect } \\
(\mathrm{km})\end{array}$} & \multirow{3}{*}{$\begin{array}{l}\text { Altitudinal } \\
\text { range } \\
(\mathrm{m})\end{array}$} & \multirow{3}{*}{$\begin{array}{l}\text { Main soil } \\
\text { association }\end{array}$} & \multicolumn{4}{|c|}{ Preliminary ecological niche model prediction } \\
\hline & & & & \multicolumn{2}{|c|}{ Positive } & \multicolumn{2}{|c|}{ Negative } \\
\hline & & & & True & False & True & False \\
\hline \multicolumn{8}{|l|}{ Dipterocarpus lamellatus } \\
\hline Sianggau FR-Dalit & 3.3 & $30-90$ & Dalit & + & & & \\
\hline Sianggau FR-Lokan & 3.5 & $50-190$ & Lokan & & & & + \\
\hline Beaufort Hills & 0.37 & $30-120$ & Dalit & & + & & \\
\hline Ganui FR & 1.2 & $180-350$ & Lokan & & & + & \\
\hline Mengalong FR & 4.2 & $0-25$ & Sipitang & & & + & \\
\hline \multicolumn{8}{|l|}{ Dipterocarpus ochraceus } \\
\hline Kinabalu Park-Transect 1 & 2.0 & $650-940$ & Crocker & & & & + \\
\hline Kinabalu Park-Transect 2 & 4.2 & $560-770$ & Kinabalu & & & + & \\
\hline Kinabalu Park-Transect 3 & 0.8 & $430-720$ & Crocker & & & & + \\
\hline Kinabalu Park-Transect 4 & 2.0 & $380-850$ & Bidu Bidu & & + & & \\
\hline Kinabalu Park-Transect 5 & 1.4 & $580-900$ & Crocker & & & + & \\
\hline Kinabalu Park-Transect 6 & 2.4 & $650-890$ & Malubok & & & + & \\
\hline Kinabalu Park-Transect 7 & 5.3 & $360-820$ & Malubok & & & + & \\
\hline Kinabalu Park-Transect 8 & 2.9 & $580-800$ & Crocker & & & & + \\
\hline Kinabalu Park-Transect 9 & 0.7 & $610-660$ & Crocker & & & + & \\
\hline Kinabalu Park-Transect 10 & 0.9 & $560-920$ & Malubok & & & + & \\
\hline Kinabalu Park-Transect 11 & 1.8 & $550-960$ & Malubok & & & + & \\
\hline Kinabalu Park-Transect 12 & 1.7 & $1,700-1,900$ & Bidu Bidu & & + & & \\
\hline Hampuan FR-Transect 1 & 1.1 & $660-1,170$ & Bidu Bidu & + & & & \\
\hline Hampuan FR-Transect 2 & 3.4 & $650-1,240$ & Malubok & & & + & \\
\hline Hampuan FR-Transect 3 & 1.5 & $850-1,300$ & Bidu Bidu & & + & & \\
\hline Mt Danum & 0.25 & $1,000-1,090$ & Bidu Bidu & & + & & \\
\hline Mt Tingkar & 0.4 & $460-800$ & Bidu Bidu & & + & & \\
\hline
\end{tabular}

